\title{
Laser photoablation of renal pelvic tumours
}

\author{
Bryce Weber, MD; ${ }^{*}$ Theresa J. McCallum, MD; ${ }^{\dagger}$ John Tulip, PhD; ${ }^{\neq}$Ronald B. Moore, MD, PhD, FRCSC ${ }^{\dagger}$
}

\begin{abstract}
We evaluated the clinical effects of the Zeiss OPMILAS (Oberkochen, Germany) multi-yttrium-aluminum-garnet (YAG) laser in the treatment of renal pelvic tumours as an alternative to nephroureterectomy. Four patients with evidence of transitional cell carcinoma (TCC) in the renal pelvis and a previous history of TCC of the bladder or opposite renal pelvis were treated with the Zeiss OPMILAS multi-YAG laser. Three patients underwent a retrograde ureteroscopic approach and 1 patient required percutaneous resection. Two wavelengths were used: $1060 \mathrm{~nm}$ continuous coagulative mode and $1440 \mathrm{~nm}$ pulsed ablative mode. The patients were followed for 12, 24, 76 and 84 months, respectively. Two patients showed no evidence of recurrence as determined by cystoscopy, retrograde pyelography and selective pelvic urine cytology. One patient experienced a recurrence of TCC requiring subsequent treatment. The ureteroscopic approach was associated with fewer complications and a more rapid recovery, compared with the percutaneous approach. All patients with solitary kidneys avoided dialysis.
\end{abstract}

CUAJ 2008;2(4):413-6

\section{Introduction}

Despite improvements in endoscopic methods, the gold standard for managing localized proximal ureteral and renal pelvic transitional cell carcinoma remains nephroureterectomy with the removal of the ureteric orifice within a cuff of bladder. ${ }^{1}$ Patients with bilateral disease, cancer in a solitary kidney or renal insufficiency may be rendered functionally anephric by traditional surgery thus encouraging conservative renal parenchyma-sparing procedures. ${ }^{1,2}$ The neodymium:yttriumaluminum-garnet ( $\mathrm{Nd}: \mathrm{YAG}$ ) laser has been used for renal-sparing surgery to treat transitional cell carcinoma of the renal pelvis (TCCP) since the early $1980 s^{3-5}$ initially accessing the renal pelvis through a nephroscope. Technological improvements of the instruments have since allowed ureteroscopic application of these lasers. ${ }^{6-8}$ In the early 1990s, a dual wavelength $\mathrm{Nd}$ :YAG (multi-YAG) laser with switchable emission at $1440 \mathrm{~nm}$ wavelength was developed at the University of Alberta for application to benign or neoplastic tumours and stone disease. ${ }^{9}$ We report on the long-term outcome of using this laser to manage these rare tumours.

\section{Case presentation and management}

Between June 1994 and February 1999, 4 patients were evaluated for and treated with ureteroscopic laser ablation of TCCP. Patient characteristics and the specific details of the laser surgery are shown in Table 1 and Table 2. All patients were women and were aged 53, 56, 72 and 73 years, respectively. Three had previous diagnoses of TCCP requiring nephroureterectomy (Table 1) and $3 \mathrm{had}$ previous diagnoses of transitional cell carcinoma of the bladder (TCCB). One patient had a prior cystectomy and ileoconduit urinary diversion in addition to subsequently undergoing a left nephroureterectomy before presenting with TCCP in the contralateral kidney. All patients received flexible ureteroscopy to confirm the diagnosis, size and location of the tumour.

Each patient received a general anesthetic to control respiratory movements during times of active laser treatment. In patients 1,2 and 3 , a 9Fr flexible ureteroscope was sufficient for visualization; however, in patient 4 a percutaneous track was required. In all patients, excellent visualization was obtained and each tumour easily identified. The flat cleaved $400 \mu \mathrm{m}$, low$\mathrm{OH}$ quartz fibre of the multi-YAG laser was passed through the operating channel and with the laser set at the $1060 \mathrm{~nm}$ mode photocoagulation was performed, painting the tumour in $2-3$ second bursts until it totally blanched. The laser setting was then switched to the $1440 \mathrm{~nm}$ mode and the tumour was ablated to the plane of normal pelvic urothelium. The laser was switched back to the $1060 \mathrm{~nm}$ mode and the base of the tumour was further irradiated. Patient 3 had superficial bladder tumour photoablation at the same time. Patient 4 required multiple treatments $(n=3)$ because of the extent of the tumour, and eventually required a repeat percutaneous tract to access recurrence in the lower pole calyx. In this patient, a ureteral stent was left indwelling and was exchanged at 3 month intervals to allow retrograde uteroscopic access through the conduit for follow-up surveillance.

Retrograde pyelography was done through the ureteroscope at the conclusion of each procedure to determine if perforation had 
occurred. A double-J (ACMI Corp., Southborough, Mass.) ureteral stent was left in place to be removed 1 month later. This was done to ensure patency of the ureter in the solitary kidney and to facilitate additional treatment and follow-up. Patient 3 had a weekly course of intravesical bacille Calmette-Guérin (BCG) instillations for 6 weeks while her stent was still in situ to facilitate treatment of her upper tract.

Patients were followed for reoccurrence by cytoscopy, retrograde pyelography and cytology at 3-month intervals for the first year, at 6-month intervals for the second year and yearly thereafter.

Follow-up investigations for the first 3 patients revealed no recurrent disease. Patients 1 and 3 were followed for longer than 10 years. One patient has now been lost to follow-up (patient 3 ) and the other continues to be monitored yearly. Patient 2 died from metastatic ovarian cancer 15 months after her laser therapy. Follow-up cystoscopy and retrograde pyelography were negative for 12 months of assessment after her procedure. Patient 4 presented with recurrent disease on ureteroscopy 9 months after the laser therapy. Consequently, the patient underwent percutaneous nephroscopic laser photoablation to ensure sufficient elimination of the tumour. The procedure was complicated by bleeding secondary to aggressive photoablation (1440 $\mathrm{nm}$ ) requiring balloon tamponade and protracted percutaneous access. The patient subsequently developed an arteriovenous fistula, which was eventually managed with embolization. On follow-up, flexible ureteroscopy and cytology from the renal pelvis revealed no evidence of recurrent tumour. However, 6 months after the salvage procedure, biopsy of a subcutaneous nodule in the patient's back revealed seeding of the percutaneous nephrostomy tract with transitional cell carcinoma. This nodule was excised along with the nephrostomy tract with plastic closure. Nevertheless, this patient passed away 2 years after the primary laser treatment owing to metastatic TCC. Prior to her death, a CT scan showed that the largest tumour deposit was in the renal fossa of the previously removed contralateral kidney, suggesting this may have been the seeding source.

\section{Discussion}

Lasers have been used in urological surgery since the early 1970s. With improved fibre optic resolution, smaller diameter fibres and the manoeuverability of flexible ureteroscopes, access to the upper collecting system for procedures involving lasers is now possible. ${ }^{7-13}$ The transureteral approach

\begin{tabular}{|c|c|c|c|c|c|c|}
\hline $\begin{array}{l}\text { Patient } \\
\text { no. }\end{array}$ & $\begin{array}{c}\text { Age, } \\
\mathrm{yr}\end{array}$ & $\begin{array}{c}\text { Indication for laser } \\
\text { surgery }\end{array}$ & $\begin{array}{c}\text { TCCP } \\
\text { tumour } \\
\text { location }\end{array}$ & $\begin{array}{l}\text { Radiographic } \\
\text { size, } \mathrm{cm}\end{array}$ & $\begin{array}{l}\text { Previous TCCP and } \\
\text { nephroureterectomy }\end{array}$ & $\begin{array}{l}\text { Previous } \\
\text { TCCB }\end{array}$ \\
\hline 1 & 56 & Solitary kidney & Right & 0.5 & Yes, left & No \\
\hline 2 & 53 & Solitary kidney & Right & 0.7 & Yes, left & Yes \\
\hline 3 & 73 & $\begin{array}{l}\text { Refusal of open } \\
\text { surgery owing to age }\end{array}$ & Left & 0.6 & No & Yes \\
\hline 4 & 72 & Solitary kidney & Right & 1.5 & Yes, left & Yes \\
\hline
\end{tabular}

\begin{tabular}{|c|c|c|c|c|c|c|c|}
\hline $\begin{array}{l}\text { Patient } \\
\text { no. }\end{array}$ & $\begin{array}{c}\text { Wavelength, } \\
\mathrm{nm}\end{array}$ & $\begin{array}{c}\text { Laser power, } \\
\text { W }\end{array}$ & $\begin{array}{c}\text { Total laser } \\
\text { time, s }\end{array}$ & $\begin{array}{l}\text { Total general } \\
\text { anesthetic, min }\end{array}$ & $\begin{array}{l}\text { Length of } \\
\text { stay, hr }\end{array}$ & Outcome & $\begin{array}{l}\text { Follow- } \\
\text { up, mo }\end{array}$ \\
\hline \multirow[t]{2}{*}{1} & 1060 & 40 & 146 & 60 & 24 & No recurrence & 84 \\
\hline & 1440 & 13 & 19 & & & & \\
\hline \multirow[t]{2}{*}{2} & 1060 & 30 & 194 & 65 & 29 & No recurrence & 12 \\
\hline & 1440 & 20 & 10 & & & & \\
\hline \multirow[t]{2}{*}{3} & 1060 & 40 & 82 & 75 & 30 & No recurrence & 76 \\
\hline & 1440 & 20 & 53 & & & & \\
\hline \multirow[t]{2}{*}{4} & 1060 & 40 & 200 & 84 & 84 & Recurrence & 24 \\
\hline & 1440 & 30 & 45 & & & & \\
\hline
\end{tabular}


was used to decrease the theoretical risk of wound implantation, to maximize parenchyma-sparing in patients with solitary kidneys and to minimize the patients' hospital stays.

Schmeller and Hofstetter ${ }^{12}$ reported that a rigid ureteroscope was preferable because the vision from a rod lens system was superior to a fibre optic device. We found that the American Cystoscope Makers, Inc. (ACMI) flexible ureteroscope provided adequate visualization and allowed for a complete survey of the entire renal pelvis and calyces. A thorough inspection of the collecting system before tumour ablation affirmed that a single, discrete lesion was present in each primary case and aided in our prognosis regarding the potential for recurrence and the ability to target the lesion. There was difficulty in obtaining sufficient deflection for treatment of the lower pole infundibulum location of the recurrent transitional cell carcino$\mathrm{ma}$ in patient 4 . Passive deflection under fluoroscopical monitoring facilitated visualization of the lower pole infundibulum and calyces. However, it was difficult to advance the $400-\mu \mathrm{m}$ fibre. A $200-\mu \mathrm{m}$ fibre is more readily advanced but was not available (owing to fibre optic coupling) in this laser model (available now on the holmium laser).

The Zeiss OPMILAS laser is unique in that the different wavelengths of light can be used for different effects during surgery without the need to switch fibres or instruments. At $1060 \mathrm{~nm}$, the multiYAG provides the deep thermal coagulation effect. As protein denaturation is accomplished, the tumour becomes pale and whitish-grey in appearance. Coagulation of the mass before ablation avoids the risk of bleeding, which would impair visualization and possibly hamper complete destruction of the tumour. Switching to the 1440-nm mode enables the laser to ablate the tissue, thereby removing tumour bulk from the operative field. A final pulse of $1060 \mathrm{~nm}$ radiation to the tumour base was given, similar to coagulating the resection bed post-transurethral resection of a bladder tumour. This technical concept was previously described by Orihuela and Smith; ${ }^{2}$ however, they had to use higher energy 1060-nm light to induce vapourization, which yields gas bubbles impairs visualization. We feel that the combination of photocoagulation and photoablation most effectively treats TCCP, reducing the potential for seeding by viable tumour cells, minimizes the possibility of posttherapy tissue sloughing and stone formation causing obstruction. Ureteral stenting was employed in patients 1,2 and 4 because they had solitary kidneys, and in patient 3 because of perforation and planned BCG therapy. The use of adjuvant therapy postablation, in an effort to reduce recurrence rate and progression, has been reported by several authors. ${ }^{3,14}$ As patient 3 was going to receive intravesical BCG for her recurrent TCCB, we elected to keep her double-J stent in place to permit reflux of the agent into her renal pelvis.

The consensus of urologists performing renalsparing techniques is that the lesion should be lowgrade, low-stage, solitary, small, perfectly defined and easily accessible ${ }^{3}$ in selected patients with a solitary kidney, synchronous bilateral disease, poor renal function or patient refusal of nephroureterectomy. ${ }^{2,3,5-7,10-13}$ As Mazeman and Biserte ${ }^{3}$ muse, a therapeutic decision must be very carefully deliberated, as all of these conditions are difficult, if not impossible, to fulfill. One of our patients may have had a higher grade and stage than would be theoretically optimal, but in each of the cases the need to retain a functional renal unit, or avoid an open procedure, or both, made the ureteroscopic approach the best for the individual patient. Each case exemplifies individual selection. The more advanced case demonstrates the ability of the multi-YAG laser to access the tumour ureteroscopically from a conduit, as well as percutaneously.

In patients with solitary kidneys, some authors advocate repeat local treatment for the first recurrence, while others feel this would be the indication for a nephroureterectomy $y^{8}$ and subsequent dialysis. We feel that these early lesions detected during TCC surveillance are akin to superficial TCCB, and may be treated and followed in a similar fashion. This position is supported by other long-term studies. ${ }^{15,16}$

In conclusion, this procedure was associated with low morbidity and preservation of renal function, and greatly decreased length of hospital stay relative to a standard nephroureterectomy. Followup for our patients is adequate to demonstrate differential recurrence rates, but the true incidence of recurrence remains uncertain and strict postoperative upper tract surveillance imperative.

From the *Division of Urology, Department of Surgery, University of Toronto, Toronto, Ont., the †Division of Urology, Department of Surgery, and the \$Department of Electrical and Computer Engineering, University of Alberta, Edmonton, Alta. 
Weber et al.

This article has been peer reviewed.

Competing interests: None declared.

\section{References}

1. Murphy DM, Zincke H, Furlow WL. Primary grade 1 transitional cell carcinoma of the renal pelvis and ureter. J Urol 1980;123:629-31.

2. Orihuela E, Smith AD. Percutaneous treatment of transitional cell carcinoma of the upper urinary tract. Urol Clin North Am 1988;15:425-31.

3. Mazeman E, Biserte J. Renal-sparing treatment of upper-tract urothelial tumors. Curr Opin Urol 1994;4:168.

4. Malloy TR, Schultz RE, Wein AJ, et al. Renal preservation utilizing neodymium: YAG laser. Urology 1986;27:99-103.

5. Woodhouse CR, Kellett MJ, Bloom HJ. Percutaneous renal surgery and local radiotherapy in the management of renal pelvic transitional cell carcinoma. $\mathrm{Br} J \mathrm{Urol}$ 1986:58:245-9.

6. Huffman JL, Bagley DH, Lyon ES, et al. Endoscopic diagnosis and treatment of uppertract urothelial tumors. A preliminary report. Cancer 1985;55:1422-8.

7. Huffman JL. Ureteroscopic management of transitional cell carcinoma of the upper urinary tract. Urol Clin North Am 1988;15:419-24.
8. Seaman EK, Slawin KM, Benson MC. Treatment options for upper tract transitionalcell carcinoma. Urol Clin North Am 1993;20:349-54.

9. Tulip J. Laser lithotripsy. US Patent 5,059,200.1991 0ct 22.

10. Grossman HB, Schwartz SL, Konnak JW. Ureteroscopic treatment of urothelial carcinoma of the ureter and renal pelvis. J Urol 1992;148:275-7.

11. Blute ML, Segura JW, Patterson DE, et al. Impact of endourology on diagnosis and management of upper urinary tract urothelial cancer. J Urol 1989;141:1298-301.

12. Schmeller NT, Hofstetter AG. Laser treatment of ureteral tumors. J Urol 1989;141:840-3.

13. Schoenberg MP, Van Arsdalen KN, Wein AJ. The management of transitional cell carcinoma in solitary renal units. J Urol 1991;146:700-2; discussion 702-3.

14. Eastham JA, Huffman JL. Technique of mitomycin C instillation in the treatment of upper urinary tract urothelial tumors. J Urol 1993;150:324-5.

15. Elliott DS, Segura JW, Lightner D, et al. Is nephroureterectomy necessary in all cases of upper tract transitional cell carcinoma? Long-term results of conservative endourologic management of upper tract transitional cell carcinoma in individuals with a normal contralateral kidney. Urology 2001;58:174-8.

16. Johnson $G B$, Grasso M. Ureteroscopic management of upper urinary tract transitional cell carcinoma. Curr Opin Urol 2005;15:89-93.

Correspondence: Dr. Bryce Weber, 2-191 Mutual St., Toronto ON M5B 2B4; bryce.weber@utoronto.co

\section{Change of address}

We require 6 to 8 weeks' notice to ensure uninterrupted service. Please send your current mailing label, new address and the effective date of change to:

\section{CUAJ}

1155 University Ave., Suite 1303

Montréal QC H3B 3A7

CUAJ JAUC

journal@cua.org 